\title{
Bayesian Network for Probability Risk Analysis of Biomass Boiler in Renewable Energy Plant
}

\author{
Nurul Ain Syhadah Mohammad Khorri ${ }^{1}$ and Nurul Sa'aadah Sulaiman ${ }^{2, *}$ \\ ${ }^{1}$ College of Engineering, Department of Chemical Engineering, Universiti Malaysia Pahang, 26300, Gambang, Pahang, Malaysia \\ ${ }^{2}$ Faculty of Chemical and Process Engineering Technology, Department of Engineering Technology, Universiti Malaysia Pahang, \\ 26300, Gambang, Pahang, Malaysia
}

\begin{abstract}
The empty fruit bunches have remarkable potential for utilisation as solid fuel boilers in the production of energy. A well operated boiler with higher efficiency is vital for a good power generation plant. However, there are numerous safety and technical issues that may lead to a lower energy production rate. A simple yet complete probabilistic risk analysis is needed to predict those issues to ensure the biomass boiler operates at its maximum efficiency. In this work, a probabilistic risk assessment model for empty fruit bunch boiler using Bayesian network approach was developed. Bayesian network provides a clear probabilistic model of cause-effect relationships of the biomass boiler system. The conditional probability values were elicitated from experts' opinion to identify the most influential factors for efficient biomass boiler operation. A case study from Renewable Energy Plant in Pahang was applied. Prediction analysis and diagnostic analysis were performed and the results show that the most important biomass boiler failure factors are corrosion and overheating. These findings are in agreement with existing literature and expert judgement. Thus, the proposed model is useful in maintaining and helping the decision maker for biomass boiler operation as well as increasing its reliability.
\end{abstract}

\section{Introduction}

Among all renewable sources in Malaysia, biomass is the most promising alternative to be utilized as the source of renewable energy [1]. As one of the world's largest producers and exporters of palm oil, Malaysia has identified that at least 168 million tonnes of biomass has been produced by palm oil industry every year. The extraction of oil from the palm fruits has resulted in a tremendous amount of palm waste such as palm kernel shell, empty fruit bunch and many others. Because of this, the amount of wastes keeps increasing each year and the issue with the disposal of these wastes has tends to burden the operators as it escalates the operating cost. Over the years, the researchers are trying to develop more efficient method of converting the biomass into energy. This makes the safety and technical issues become important in order to convert the waste into energy.

Nevertheless, the high availability of the empty fruit bunch (EFB) as the feedstock for energy production can endorse the concept of waste-to-wealth [2]. This makes the power generation using EFB is now eagerly anticipated. EFB offers significant advantages as a combustion feedstock for power generation due to the high volatility and reactivity of the fuel [3]. Due to its low sulphur content, EFB is a sustainable bio- fuel resource [4] and environmental friendly than fossil fuel power plants in regards to global warming potential and acidification potential [5]. Some of the available technologies for energy generation from biomass are direct combustion, gasification, and pyrolysis [6]. However, direct combustion is the most preferable method for biomass combustion in power generation. This is because this method is simpler compared to other method and it has the same principle as the normal combustion. In direct combustion, the boiler system is the most important part that needs an extra attention and to be fully understood in order to obtain an efficient production system.

A small improvement on the boiler efficiency will help to save large amount of fuel as well as their safety and reliability. To make a rational decision making in designing or handling the boiler, a complete understanding of the causes of failure and its consequences must be taken into account to improve the boiler. There are many factors could contribute to the failure of an EFB boiler such as limited combustion area, combustion stability, overheating and corrosion [7-9]. Such factors have caused many energy plants were considered to be shut down due to its complexity in operating the boiler. Therefore, it is necessary to construct a risk assessment in order to increase boiler efficiency and to reduce the technical problems for a better boiler lifetime.

There are a few researches for risk assessment of the biomass power plant had been carried out. According to [10], the design service life of the old power station is reaching and an appropriate decision must be made based

* Corresponding author: saaadah@ump.edu.my 
on the updated information of their equipment and components condition. Thievel and coworkers [11] implemented Failure Modes and Effects Analysis (FMEA) in risk analysis of a biomass combustion process. This method is very useful to early identification and elimination of potential failure modes of the biomass combustion. However, FMEA is not capable to discover complex failure modes including multiple failures resulting by one cause. Moreno and Cozzani [12] introduced fishbone diagram in the biomass risk analysis and this method allow others to see all causes simultaneously. However, this method does not include quantitative section for future prediction on risk analysis. In most of the risk assessment process, the possible failure of any equipment or component is being focused. The key requirement of any operational risk analysis is that it should include the ability to consider the cumulative effect of many risk factors that might be minor to the system but collectively a cause for concern [13]. This suggests that the risk analysis should be at least semiquantified or fully quantified so that the risks can be properly assessed.

In recent years, development in improvement of probabilistic techniques and algorithms primarily based on Bayesian technique and fostered by the artificial intelligence network. Applications of Bayesian network $(\mathrm{BN})$ has been widely used in probability risk analysis in the past few years [14-15]. There are several adaptations of Bayesian networks modelling in risk analysis showing that Bayesian networks have demonstrated its capabilities and efficiencies as a practical engineering and problemsolving tool [16]. The techniques were performed to allow automated reasoning, broadening and deepening the scientific basis for decision making [17]. $\mathrm{BN}$ is a type of Probabilistic Graphical model that can be used to build models from data and expert opinion [18]. BN is useful in the field where prediction is needed and the outcome is uncertain. BN helps in making intelligent, quantifiable and justifiable decisions instead of a random guessing.

Thus, this paper aims to develop a risk assessment model for boiler in biomass power plant generation using Bayesian Network approach. Through this method, Bayesian network could provide a new way to model the cause-consequence chains for a better energy production. Bayesian network can be effectively used to analyse situations, such as alternative operational decisions or consequences of system changes. It helps the decisionmakers to prioritize on which risk should be considered in a timely manner [19].

\section{Methodology}

\subsection{Data gathering}

The data of factor contributed to the biomass power plant boiler were gathered from existing literature, reports and experts experience. For experts' opinion data gathering, an interview session was set up at Renewable Energy Plant in Pahang with the experts to further understand the factors that contributed to the boiler failure and its inefficiency.

\subsection{Development of Bayesian Network model}

Bayesian network is a graphical representation of events that occurred and it is constructed as a directed acyclic graph. Each node in Bayesian network represents an event (variable) with possible continuous or discrete states [10]. Causal relationships between the factor nodes are defined by an arrow called arc, leading from the parent node (cause node) to the child node (consequences or effect node). The states of each variable in Bayesian network were determined according to its suitability and it describes the process in real world. Some suggested states include Yes or No, Stable or Unstable and High or Low. In this work, commercial software GeNIe was applied to construct Bayesian network.

\subsection{Conditional probability tables (CPTs) formulation}

The relationship between the parent node and the child node is quantified by a Conditional Probability Table (CPT). The CPT is used to define the joint probability distribution for all nodes in Bayesian network. The whole concept of Bayesian network was built based on Bayes theorem, where the CPT of the causes was expressed using the observed evidence. CPT describes the probability of a variable within a state, given a combination of values of parent states. Given a simple BN as in Figure 1, the CPT of the network is shown in Table 1 with relationships of Equation 1:

$$
P x_{c}^{n}\left(\mid x_{p 1}^{n}, x_{p 2}^{n}\right)=\mathrm{CPT}_{n} ;(n=1,2,3, \ldots)
$$

where, $P$ is probability, $x^{n}$ is one state of network variable $x, c$ is child node, and $p$ is parent node.

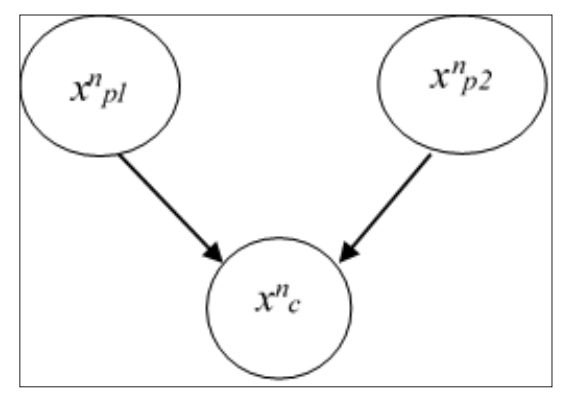

Fig. 1. Simple BN of two parent nodes and one child node

A questionnaires were designed and distributed to the experts for CPT elicitation. The responses from the questionnaire were collected based on the probability scale as in Table 2. After all the CPT of each node has been defined, the network was then simulated and the Bayesian Network was ready for the predictive analysis and diagnosis analysis.

Table 1. Example of CPT for a child (consequence) node with two parent (cause) node. 


\begin{tabular}{|l|c|c|c|c|}
\hline Parent 1 & \multicolumn{2}{|c|}{$\begin{array}{c}\text { STABLE } \\
\left(x_{p 1}^{1}\right)\end{array}$} & \multicolumn{2}{c|}{$\begin{array}{c}\text { UNSTABLE } \\
\left(x_{p 1}^{2}\right)\end{array}$} \\
\hline Parent 2 & $\begin{array}{c}\text { YES } \\
\left(x_{p 2}^{1}\right)\end{array}$ & $\begin{array}{c}\text { NO } \\
\left(x_{p 2}^{2}\right)\end{array}$ & $\begin{array}{c}\text { YES } \\
\left(x_{p 2}^{1}\right)\end{array}$ & $\begin{array}{c}\text { NO } \\
\left(x_{p 2}^{2}\right)\end{array}$ \\
\hline STABLE $\left(x_{c}^{1}\right)$ & $\mathrm{CPT}_{1}$ & $\mathrm{CPT}_{3}$ & $\mathrm{CPT}_{5}$ & $\mathrm{CPT}_{7}$ \\
\hline UNSTABLE $\left(x_{c}^{2}\right)$ & $\mathrm{CPT}_{2}$ & $\mathrm{CPT}_{4}$ & $\mathrm{CPT}_{6}$ & $\mathrm{CPT}_{8}$ \\
\hline
\end{tabular}

Table 2. Probability scale and their descriptions.

\begin{tabular}{|c|c|c|}
\hline $\begin{array}{c}\text { Qualitative } \\
\text { Values }\end{array}$ & $\begin{array}{c}\text { Quantitative } \\
\text { Values } \\
\text { (Probability) }\end{array}$ & Description \\
\hline Very High & $0.96-1.0$ & $\begin{array}{c}\text { The stated event is } \\
\text { almost certain to cause } \\
\text { the threat event. }\end{array}$ \\
\hline High & $0.80-0.95$ & $\begin{array}{c}\text { The stated event is } \\
\text { highly likely to cause } \\
\text { the threat event. }\end{array}$ \\
\hline Moderate & $0.21-0.79$ & $\begin{array}{c}\text { The stated event is } \\
\text { somewhat likely to } \\
\text { cause the threat event. }\end{array}$ \\
\hline Low & $0.05-0.2$ & $\begin{array}{c}\text { The stated event is } \\
\text { unlikely to cause the } \\
\text { threat event. }\end{array}$ \\
\hline Very Low & $0-0.049$ & $\begin{array}{c}\text { The stated event is } \\
\text { highly unlikely to cause } \\
\text { the threat event. }\end{array}$ \\
\hline
\end{tabular}

\subsection{Bayesian Network analyses}

Two types of analysis were carried out it this study namely prediction and diagnosis analysis. For prediction analysis, the model probability was modified according to the known root cause of the failure. To observe the impact of an event to the failure, the probability of some primary event were change to be in $100 \%$ probability. Meanwhile for diagnostic analysis, the probability of an event was calculated backward, by specifying the probability of the particular event that contributes to the failure when the occurrence of the failure is known i.e. $100 \%$ probability.

\subsection{Model Validation}

The face validation model was conducted to evaluate the results generated from the proposed model by comparison with historical data or a case study. The graphical model and the results obtained were as well verified by the domain experts. Countermeasure actions were suggested based on the model network to increase the efficiency of the biomass boiler.

\section{Results and discussions}

\subsection{Bayesian Network model of EFB Boiler failure factors}

A case study of water tube boiler was utilized in this work. A water tube boiler is a type of boiler where water flows in the tubes and it passes through the boiler that contains fires. When the fuel burned, the hot gases will be generated and heat the water in the tube. As the water temperature increases, water generates more steam and it is transferred into the steam drum. The identified factors that may contribute to inefficiency of EFB boiler were categorised into three major factors namely combustion stability, limited combustion area and overheating and corrosion. The possible threats of boiler inefficiency are summarised in Table 3.

Table 3. Categories of EFB boiler failure.

\begin{tabular}{|c|c|c|}
\hline Major Factor & Threats & Consequences \\
\hline $\begin{array}{l}\text { Combustion } \\
\text { Stability }\end{array}$ & $\begin{array}{ll}\text { - } & \text { Inefficient } \\
& \text { Biomass Pre- } \\
\text { treatment Process } \\
\text { - } & \text { High Moisture } \\
\text { Content } \\
\text { - } \\
\text { Unsuitable Fuel- } \\
\text { Air Ratio } \\
\text { - } \\
\text { - } & \text { Limitable Flame } \\
& \text { Combustion Area }\end{array}$ & \\
\hline $\begin{array}{l}\text { Limited } \\
\text { Combustion } \\
\text { Area }\end{array}$ & $\begin{array}{ll} & \text { Incombustible } \\
& \text { Mineral Matter } \\
\text { - } & \text { Ashes Formation } \\
\text { - } & \text { Clinker } \\
\text { - } & \text { Poor Boiler } \\
& \text { Design } \\
\end{array}$ & $\begin{array}{c}\text { Energy } \\
\text { Conversion }\end{array}$ \\
\hline $\begin{array}{l}\text { Overheating } \\
\text { \& Corrosion }\end{array}$ & $\begin{array}{ll}\text { - } & \text { Inefficient Water } \\
\text { Treatment } \\
\text { Process } \\
\text { - High Amount of } \\
\text { Total Dissolve } \\
\text { Solid } \\
\text { - High Operating } \\
\text { Pressure } \\
\text { - } \quad \text { Mineral } \\
\text { Deposition } \\
\text { - Foaming } \\
\text { - Scaling } \\
\text { - } \text { Tube Clogging }\end{array}$ & Leakage \\
\hline
\end{tabular}

The Bayesian Network was constructed based on the factors listed in Table 3 . The proposed model showing the relationships of the identified failure factors and its associate consequences is depicted in Figure 2.

\subsection{Bayesian Network predictive and diagnostic analysis}

The predictive and diagnosis analyses were performed to predict the boiler condition given certain event and to identify the path of accident, respectively [20]. Before introduction of any evidence, the proposed model was simulated using the prior values based on the historical data and expert opinion. The initialized probability of EFB boiler in failure condition is $69 \%$ which led to $62 \%$ of inefficient energy conversion, $48 \%$ probability of 
explosion and $69 \%$ leakage probability as the consequences.

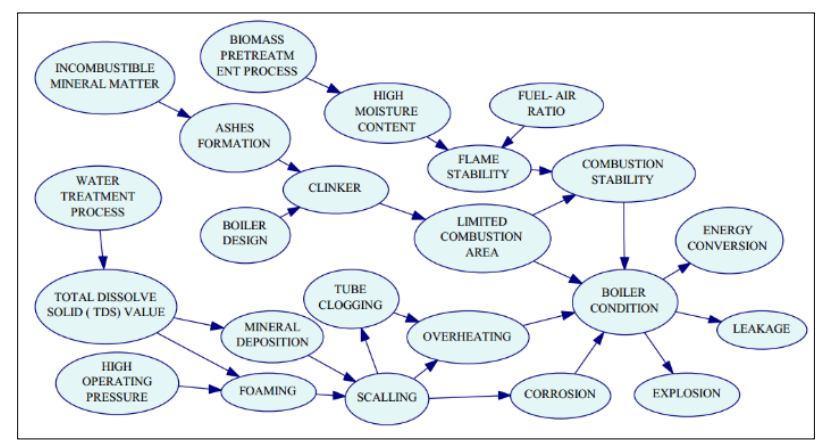

Fig. 2. Proposed Bayesian Network model for risk analysis of boiler failure.

In conducting predictive analysis, three scenarios have been chosen for the analysis which are Biomass Pretreatment Process, Incombustible Mineral Matter, and Water Treatment Process. The three scenarios are 100\% probability of inefficient Biomass Pretreatment Process, $100 \%$ probability of high Incombustible Mineral Matter, and $100 \%$ probability of inefficient Water Treatment Process. It is observed in Figure 3 that the probability of boiler in failure condition has increased from $69 \%$ to $78 \%$. As expected, the probability in the consequences of boiler failure which are the Energy Conversion, Leakage and Explosion also increases. It is suggested by [21] that the issues of EFB composition and pre-treatment that making poor combustion effect. The model shows that the three factors have significant influences towards the major boiler condition. This demonstrates the strength of the Bayesian network in predicting future event that help in decision making and in preparing any step to take action or to schedule maintenance activities.

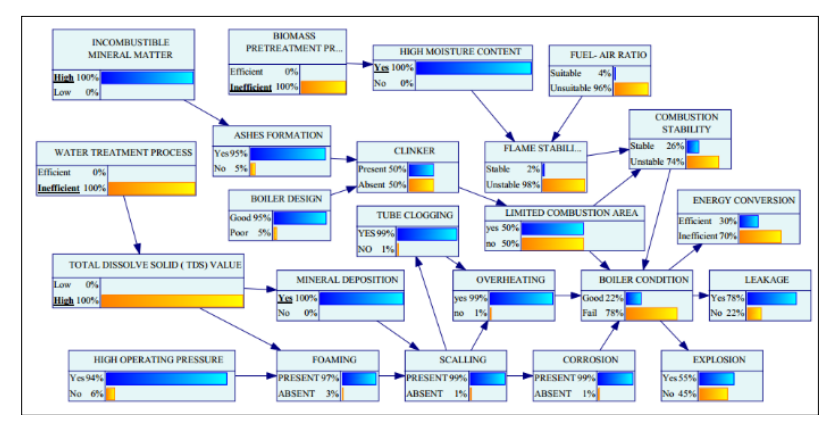

Fig. 3. Predictive analysis of EFB boiler condition.

The sources of failure that caused particular consequence are observed in diagnosis analysis. Referring to Figure 4, when the boiler condition was set to be $100 \%$ fail, the probability of all the major factors of boiler failure increases. Both Corrosion and Overheating nodes show $99 \%$ probability of occurrence. Meanwhile Limited Combustion Area node increase from 50\% to 55\%. The underlying factors identified are Scaling, Foaming, Mineral Deposition, High Operating Temperature and Total Dissolve Solid (TDS) value. The results obtained is in accordance with the experts' opinion whereby water treatment is very much important in boiler operation. Thus the practical fault diagnosis and checking should be focus on the probability of these suspected factors to control the risk of boiler failure.

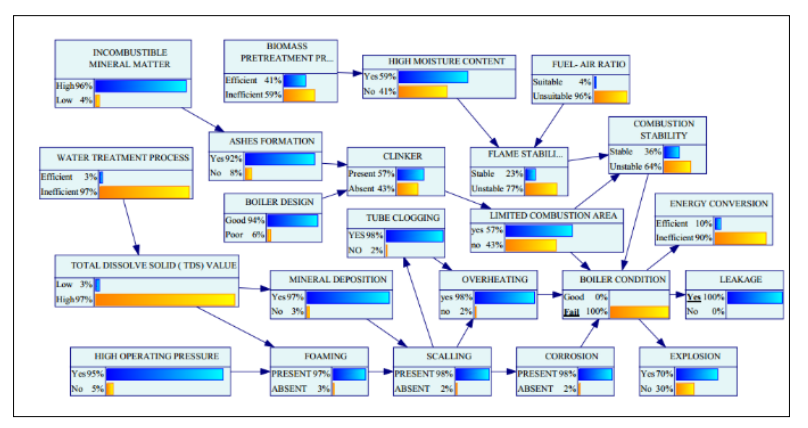

Fig. 4. Diagnosis analysis for boiler failure.

\subsection{Validation of model by experts}

The proposed $\mathrm{BN}$ need to be verified by testing if the BBN predictions are matched with results from other available sources of information. However, in this work, industrial experts are preferable with the help to verify and validate the networks based on their experience. The proposed model was validated by the boiler expert and compared with a case study. From their experience and historical situation of the plant, the experts accepted and verified that most of the boiler failure are caused by corrosion and overheating. This is also in agreement with [8] suggested that formation of deposits in the boiler component are potential to cause corrosion. This problem is caused by the presence of incombustible mineral matter in the biomass fuel. To overcome the problem caused by the clinker of deposits formation, it is suggested to have a good boiler design that could remove ashes that may form clinker. It is also crucial to pre-treat the EFB in order to reduce the moisture content to be less than $40 \%$. This is because high moisture content could reduce both flame stability and combustion stability.

\section{Conclusions}

In order to ensure the boiler operates at its maximum efficiency, a good risk analysis is needed to make a good decision in maintaining the boiler. This study helps in determining the root cause of a boiler failure which might lead to a catastrophic failure such as leakage and explosion. The graphical model illustrates the relationship between the cause and the effect of the failure in a systematic way in both qualitative and quantitatively. It is flexible and effective in identifying the major factors that could cause critical consequences to the boiler failure. The developed network shows excellent predictive calculation for boiler failure in the predictive analysis.

Bayesian network is also very reliable for diagnosis analysis as it has the ability to perform reverse inference and does not require complete information where by operator do not have access to a large amount of 
information in real time. From the result obtained, the greatest contributors of the failure are Overheating and Corrosion as both has the highest increment in probability indicating the significant source of failure. This research could help the biomass industry in performing a good risk analysis of an energy plant. Not only it can assist the operator and engineers in making a risk analysis of a boiler, but it also can help in making risk analysis for an energy plant to maximize the production efficiency in the energy plant.

The research work was financially supported by Universiti Malaysia Pahang through research grant RDU1901206 and the Ministry of Higher Education Malaysia under the Fundamental Research Grant Scheme (FRGS) project, FRGS/1/2019/TK02/UMP/02/27.

\section{References}

1. S.M. Shafie, T.M.I Mahlia, H.H. Masjuki, A. Ahmad-Yazid, Renew. Sust. Energ. Rev. 16, 8 (2012)

2. E. Dermawan, R. Abdullaa, H. Marbawi, M.K. Sabullah, Renew. Energ. 129, A (2018)

3. A. Demirbas, Prog. Energy. Combust. Sci. 31, 2 (2005)

4. Y.P. Olisa, W. Island, K.W. Kotingo, W. Island, B. State, Eur. J. Eng. Technol. 2, 2 (2014)

5. P.N. Agus, B.P. Teguh, A.R. Alfonsus, IOP Conf. Ser. Earth. Environ. Sci. 336, 1 (2019)

6. P. Basu, Biomass Gasification, Pyrolysis and Torrefaction: Practical Design and Theory (2nd Edition, Academic Press, Amsterdam, 2013.

7. Y. Alipour, P. Henderson, P. Szakálos, Mater. Corros. 65, 2 (2013)

8. L.J.R. Nunes, J.C.O. Matias, J.P.S. Catalão, Renew. Sust. Energ. Rev. 53 (2016)

9. S. Mekhilef, R. Saidur, A. Safari, W.E.S.B. Mustaffa, Renew. Sust. Energ. Rev. 15, 7 (2011)

10. M. Sýkora, J. Marková, D. Diamantidis, Reliab. Eng. Syst. Safe. 169 (2018)

11. P.X. Thivel, Y. Bultel, F. Delpech, J. Haz. Mat. 151 (2007)

12. V.C. Moreno, V. Cozzani, J. Loss. Prev. Proc. Ind. 35 (2015)

13. A. Bolsover, Proc. Safety. Prog. 34 (2015)

14. B. Khan, F. Khan, B. Veitch, M. Yang, Reliab. Eng. Syst. Safe. 169 (2018)

15. Z.Z. Wang, G. Chen, Tunn. Undergr. Sp. Tech. 70 (2017)

16. N. Khakzad, G. Landucci, G. Reniers, Reliab. Eng. Syst. Safe. 167 (2017)

17. H.J. Pasman, W.J. Rogers, Int. J. Hydrogen. Energ. 37 (2013)

18. A. Jaitha, An Introduction to the Theory and Applications of Bayesian Networks (CMC Senior Theses, 2017)
19. D. Heckerman Stud. Comput. Intell. 156 (2008)

20. N. Khakzad, F. Khan, P. Amyotte, Reliab. Eng. Syst. Safe. 96, 8 (2011)

21. I.A. Pratiwi, H.D. Ardiansyah, Ecol. Environ. Conserv. 25 (2019) 